\title{
Effects of Aging and Mild Cognitive Impairment on Electrophysiological Correlates of Performance Monitoring
}

\author{
Franka Thurm $^{\mathrm{a}, \mathrm{b}, \mathrm{c}, *}$, Daria Antonenko ${ }^{\mathrm{a}, 1}$, Winfried Schlee ${ }^{\mathrm{b}}$, Stephan Kolassa ${ }^{\mathrm{d}, 2}$, Thomas Elbert $^{\mathrm{a}}$ \\ and Iris-Tatjana Kolassa ${ }^{\mathrm{a}, \mathrm{b}, \mathrm{e}}$ \\ ${ }^{a}$ Department of Psychology, University of Konstanz, Konstanz, Germany \\ ${ }^{\mathrm{b}}$ Clinical and Biological Psychology, Institute of Psychology \& Education, University of Ulm, Ulm, Germany \\ ${ }^{\mathrm{c}}$ Department of Psychology, TU Dresden, Dresden, Germany \\ ${ }^{\mathrm{d}}$ Research \& Innovation, SAF Simulation, Analysis \& Forecasting AG, Tägerwilen, Switzerland \\ e Zukunftskolleg, University of Konstanz, Konstanz, Germany
}

Accepted 5 February 2013

\begin{abstract}
Performance monitoring tasks are suitable for investigating aging-related decline in executive functions. However, little is known about performance monitoring in premature pathological aging and mild cognitive impairment (MCI). This study recorded the error-related negativity (ERN) and the correct-related negativity (CRN) as indices of performance monitoring and compared these responses in older adults with MCI to the ones of younger and older adult controls. No differences in either ERN or CRN were found between younger and older adult controls. Compared to both control groups, we observed a more negatively pronounced CRN in MCI subjects. Only in this group did the amplitude of the CRN not differ from the one of the ERN. In general, larger differences between both components (i.e., ERN $>\mathrm{CRN}$ ) were associated with better performances in cognitive tests requiring inhibition and executive control. These results indicate that electrophysiological correlates of performance monitoring (ERN and CRN) are differentially affected by aging and MCI.
\end{abstract}

Keywords: Aging, EEG, event-related potentials, executive function, mild cognitive impairment, neuropsychological test

Supplementary data available online: http://www.j-alz.com/issues/35/vol35-3.html\#supplementarydata06

\section{INTRODUCTION}

Normal aging is accompanied by cognitive and neural changes. Several cross-sectional and longitudinal studies report not only a significant shrinkage of the human brain, especially in prefrontal regions $[1,2]$,

\footnotetext{
${ }^{1}$ Current affiliation: Department of Neurology, Charité University Medicine, Berlin, Germany.

${ }^{2}$ Current affiliation: SAP Switzerland AG, Tägerwilen, Switzerland.

*Correspondence to: Franka Thurm, Department of Psychology, TU Dresden, Zellescher Weg 17, 01069 Dresden, Germany. Tel.: +49 351463 39192; Fax: +49 351463 42194; E-mail: thurm@psychologie.tu-dresden.de.
}

but also a related decline in executive functions with increasing age [3-7]. Age-related decline in executive functions can be measured, for example, by tests of set shifting [8, 9] and verbal fluency $[10,11]$ as well as by reaction time (RT) tasks with response conflicts [12]. A decline in executive functions might mediate age-related changes in other cognitive variables, particularly in memory functions [13-16].

Mild cognitive impairment (MCI) is a syndrome which might indicate early pathological aging. It is associated with deterioration in at least one cognitive domain [17-19] and with neuropathological abnormalities [20, 21]. MCI subjects do not yet fulfill the criteria of dementia but are at high risk of developing 
neuropathology later in life [18]. Different etiological components may promote MCI, which is consequently heterogeneous in its clinical manifestations. Possible driving factors of MCI include neurodegenerative disorders such as Alzheimer's disease (AD), vascular dementia, traumatic brain injuries, metabolic dysregulation, and psychiatric problems [19, 22]. Given this heterogeneity of causes, there is still an ongoing debate about the meaningfulness of MCI as a clinical syndrome per se. So far, no consensus about MCI diagnostic criteria has been achieved. Based on previous research from various groups [23-29], the US-National Institute on Aging and the Alzheimer's Association has recently proposed research criteria for the particular MCI subtype, which is suspected as an early stage of $\mathrm{AD}[30,31]$. These criteria incorporate biomarkers in cerebrospinal fluid such as amyloid- $\beta$ and tau, positron emission tomography with fluodeoxyglucose (FDG-PET), and also structural magnetic resonance imaging (MRI). However, these biomarkers (i) involve high costs or invasive methods, (ii) are not suitable for general clinical practice (see also [32]), and (iii) still lack the benefit of providing clear diagnostic cutoff values to discriminate between normal aging, MCI due to premature pathological aging, preclinical stages of AD, and MCI due to other causes. Further validation of the proposed MCI criteria and the development of additional non-invasive diagnostic methods are still needed. Evoked potentials may indicate deficient executive functions and therefore may offer one such method.

Performance monitoring includes error detection and error compensation (i.e., error correction) and is one aspect of executive control that is necessary to master the wide array of daily tasks. Dysfunctional performance monitoring potentially leads to inappropriate adjustments of subsequent actions and to behavioral problems [12]. Errors in choice RT tasks are reflected in the "error-related negativity" or error negativity (ERN: [33]; Ne: [34]) in the electroencephalogram (EEG). The ERN is a component of the event-related brain potential (ERP) starting around the onset of the erroneous response, peaking within $100 \mathrm{~ms}$ and showing a fronto-central negativity [33-38]. Its generator has consistently been localized in the medial frontal cortex, more specifically in the anterior cingulate cortex (including the anterior midcingulate cortex or aMCC) which is postulated to be strongly involved in both performance and/or conflict monitoring and subsequent performance adjustment [39-43]. The ERN is considered to be an electrophysiological marker of error detection, reflecting discrepancies between the actual (erroneous) and the required (correct) response [34, 44, 45].

A second but smaller medial-frontal negativity related to response monitoring can also be elicited after correct responses [35, 46, 47]. Unlike the ERN, which is most likely to be observed after premature responses, so-called "slips" [41, 45], Coles et al. [44] suggested that the correct-related negativity (CRN) is most likely to occur in cases of response uncertainty or might reflect partial error processing during correct responses (see also [45, 48, 49]). In contrast to the ERN, the CRN presumably plays a more general role in performance monitoring and in the initiation of future performance adaptation $[35,50]$. Both performance monitoring and adaptation have been shown to be more difficult with increasing age $[51,52]$.

Several studies reported reduced ERN amplitudes in healthy older compared to younger adults $[48,51$, 53-57] and older adults with AD or Parkinson's disease [58-60]. However, others did not find this age-related decrease in ERN amplitude [61-64]. The CRN has been investigated in only a few studies with regard to aging and dementia. These studies have found inconsistent results: The CRN was increased [55, 61], decreased [58], or unaffected in aged compared to young participants [53]. In AD patients, the CRN was either unaffected [59] or reduced [58]. Furthermore, Mathalon et al. [58] found no difference between ERN and $\mathrm{CRN}$ in $\mathrm{AD}$ patients although the typical pattern of a more negative ERN amplitude compared to the CRN was observed in younger and older controls without dementia.

The impact of aging and dementia on performance monitoring is unclear in the current literature. Both ERN and CRN might serve as additional psychophysiological indices to investigate the effects of healthy compared to early pathological aging on performance monitoring $[65,66]$. In the absence of other studies investigating the ERN and CRN in MCI, we measured electrophysiological ERPs on correct and incorrect trials (i.e., CRN and ERN) in an adapted version of the Eriksen flanker paradigm [67] and analyzed associations of these ERPs with the neuropsychological test performance of younger adults, older adults, and MCI subjects.

Based on previous findings, which indicated reduced behavioral performance and reduced differentiation between electrophysiological correlates of performance monitoring following erroneous and correct trials (i.e., between ERN and CRN, respectively) in AD patients [58], we expected that (1) MCI subjects show worse behavioral performance (RT and error rates) in 
the Flanker task and a reduced Error-Correct difference (i.e., reduced ERN or enhanced CRN amplitudes or both) compared to older adult controls. (2) We further expected RT slowing in the older compared to the younger control group. However, since participants were thoroughly cognitively examined and MCI was excluded from the older control group (which was not exactly the case in most of the previous studies [36, 51, 53-57]), we expected preserved error detection (i.e., unaltered ERN components) in healthy older controls (cf.[61, 64]). We further explored possible variations of the $\mathrm{CRN}$ with normal aging. (3) We hypothesized that smaller Error-Correct difference waveforms are associated with worse performance in neuropsychological tests of executive function. (4) Finally, we expected that the ERN and CRN show fronto-central maxima (at electrodes $\mathrm{Fz}, \mathrm{FCz}$, and $\mathrm{Cz}$ ) and that the $\mathrm{CRN}$ shows a more frontal orientation compared to the ERN [55].

\section{MATERIALS AND METHODS}

\section{Participants}

ERP data were analyzed from three different groups: (1) 14 older adults aged 60-88 years (5 males, 9 females) with MCI (12 cases of amnestic MCI and 2 cases of nonamnestic MCI) according to its clinical manifestations [17-19]; (2) 16 healthy older adults aged 63-78 years ( 7 males, 9 females); and (3) 16 younger adults aged 20-26 years (students; 7 males, 9 females). All participants had normal or corrected to normal vision, and all participants but one older adult were right-handed according to the Edinburgh Handedness Inventory [68]. Groups did not differ in years of education $\left(F_{(2,43)}=1.34, p=0.27\right)$ or distribution of gender $\left(\chi^{2}(2)=0.26, p=0.88\right)$. Healthy older controls and older adults with MCI had a comparable age range $\left(t_{(28)}=-1.38, p=0.36\right)$. Group characteristics are summarized in Table 1.

Participants were recruited at the University of Konstanz, Germany, during informational events in local senior centers and with the help of flyers and advertisement in local newspapers. The ethics committee of the University of Konstanz, Germany, approved this study. Written informed consent was obtained prior to study participation.

\section{Controls}

In a structured interview, all subjects were screened for medical conditions. All interviews were carried out by trained psychologists. Psychiatric illnesses were further assessed using the Mini International Neuropsychiatric Interview (German version 5.0.0 according to DSM-IV [69]). Exclusion criteria for controls included: lack of fluency in spoken or written German, significant memory complaints [70, 71], MCI [17-19], dementia according to both the NINCDSADRDA [72] and DSM-IV-TR criteria [73], a history of other significant neurological disorders, current psychiatric disorders, substance abuse or dependency, or antidementia or psychiatric medication.

\section{MCI subjects}

All MCI subjects affirmed that they have memory complaints (according to [61]) and fulfilled the clinical MCI criteria [17-19]. The exclusion criteria used for the MCI subjects were the same as for the control groups with, of course, the exception of memory complaints, MCI, and antidementia medication. The latter was permitted when the medication dosage had remained constant for at least three months. Possible depressive symptoms were evaluated with the Geriatric Depression Scale-15 (GDS-15; 15-item short German version [74, 75]). All MCI subjects were rated below the GDS-15 cutoff score of five points ( $M=1.9, S D=1.4$; no depression). Structural MRI data available for 10 out of $14 \mathrm{MCI}$ subjects served to exclude brain abnormalities such as stroke and malignant brain tumors. No MRI scans were obtained from the remaining four participants due to metal objects within the body. However, their medical reports were inconspicuous.

\section{Neuropsychological examination}

The following neuropsychological tests were performed by all participants (see also Table 1): the Mini Mental State Examination test (MMSE, range 0-30; e.g., [76]), the Consortium to Establish a Registry for Alzheimer's Disease (CERAD-Plus; e.g., [77]) with the subtests Boston naming test (range 0-15), verbal fluency (semantic fluency and phonemic fluency), and Trail Making Test A and B (TMT-A/B), free immediate word recall (range 0-10), word recognition $(0-100 \%)$, as well as the German version of the Wechsler Adult Intelligence Scale (HAWIE-R) subtests digit span (range 0-28) and digit-symbol substitution test (range 0-93) [78]. Younger adult controls demonstrated superior performance in almost all cognitive tests (see Table 1). Post-hoc tests revealed that older controls showed reduced performance in the free word recall $\left(t_{(30)}=4.06, p<0.001\right)$, in speedrelated tests, namely in the TMT-A $\left(t_{(30)}=-4.21\right.$, 
Table 1

Demographic, cognitive and behavioral data

\begin{tabular}{|c|c|c|c|c|c|}
\hline Group & Young $^{\mathrm{a}}$ & Old $^{\mathrm{a}}$ & $\mathrm{MCI}^{\mathrm{b}}$ & $F_{(2,43)}$ & $p$-value \\
\hline Age (years) & $22.3 \pm 2.1$ & $68.0 \pm 3.4$ & $70.6 \pm 8.2$ & 444.95 & $<0.0001$ \\
\hline Education (years) & $15.2 \pm 1.9$ & $14.8 \pm 2.7$ & $13.8 \pm 2.3$ & 1.34 & 0.27 \\
\hline MMSE & $29.8 \pm 0.5$ & $29.3 \pm 0.8$ & $28.4 \pm 1.2$ & 9.38 & $<0.001$ \\
\hline Boston naming test & $14.6 \pm 0.8$ & $14.7 \pm 0.5$ & $14.1 \pm 1.6$ & 1.44 & 0.25 \\
\hline Free word recall & $7.9 \pm 1.4$ & $5.8 \pm 1.5$ & $5.1 \pm 1.7$ & 14.34 & $<0.0001$ \\
\hline Word recognition $(\%)$ & $100.0 \pm 0$ & $96.3 \pm 0.6$ & $80.9 \pm 2.0$ & 11.12 & 0.0001 \\
\hline TMT-A (s) & $27.8 \pm 10.1$ & $45.2 \pm 10.7$ & $50.9 \pm 14.3$ & 16.30 & $<0.0001$ \\
\hline TMT-B (s) & $57.4 \pm 16.6$ & $97.4 \pm 34.8$ & $136.5 \pm 58.5$ & 15.04 & $<0.0001$ \\
\hline Verbal fluency & $40.8 \pm 7.0$ & $38.3 \pm 7.4$ & $30.9 \pm 7.6$ & 7.41 & 0.002 \\
\hline Digit span test & $16.4 \pm 4.2$ & $13.8 \pm 2.9$ & $13.8 \pm 3.7$ & 2.58 & 0.09 \\
\hline Digit-symbol test & $64.9 \pm 10.8$ & $45.1 \pm 10.8$ & $39.2 \pm 7.1$ & 28.70 & $<0.0001$ \\
\hline Flanker error & $38.7 \pm 20.4$ & $19.4 \pm 14.2$ & $29.5 \pm 16.3$ & 5.05 & 0.01 \\
\hline Flanker correct & $242.1 \pm 24.5$ & $261.3 \pm 15.8$ & $251.9 \pm 19.0$ & 3.65 & 0.03 \\
\hline Flanker RT error $(\mathrm{ms})^{\mathrm{c}}$ & $316.9 \pm 46.8$ & $459.8 \pm 181.9$ & $561.0 \pm 204.1$ & 17.57 & $<0.0001$ \\
\hline Flanker RT correct $(\mathrm{ms})^{\mathrm{d}}$ & $398.6 \pm 45.3$ & $520.0 \pm 114.6$ & $609.2 \pm 135.7$ & 30.97 & $<0.0001$ \\
\hline
\end{tabular}

Values are means \pm standard deviations. Flanker, adapted Eriksen Flanker RT task; RT, reaction time of erroneous (error) and correct trials; total numbers of erroneous/correct responses given. ${ }^{\mathrm{a}} n=16$ ( 7 males), ${ }^{\mathrm{b}} n=14$ (5 males), ${ }^{\mathrm{c}} \mathrm{df}=2,80^{\mathrm{d}} \mathrm{df}=2,89$.

$p<0.001)$ and TMT-B $\left(t_{(30)}=-2.87, p=0.02\right)$ and in the digit-symbol test $\left(t_{(30)}=5.68, p<0.0001\right)$ compared to younger adults. Younger and older controls showed no difference in MMSE score, word recognition, or verbal fluency. Compared to older controls, MCI subjects showed further reduced performance in the MMSE $\left(t_{(28)}=-2.75, p=0.02\right)$, the word recognition test $\left(t_{(28)}=-3.61, p=0.002\right)$, and in tests of executive function, namely in the verbal fluency test $\left(t_{(28)}=-2.79, p=0.02\right)$ and the TMT-B $\left(t_{(28)}=2.71\right.$, $p=0.03)$. There was no difference between groups in the Boston naming and the digit span test.

Task

As shown in Fig. 1, we used an adapted Eriksen flanker RT paradigm [67] and presented 272 stimuli (arrays of five arrowheads) using Presentation ${ }^{\circledR}$ software (Neurobehavioral Systems, Inc.). Each participant underwent two training blocks followed by four successive 3.5-minute blocks, all consisting of four subsections with 17 trials each. Participants were asked to correctly indicate the direction of the middle arrowhead by pressing the left or right mouse button with their right index or middle finger, respectively. In addition, they were asked to respond as fast as possible without guessing. After each 17-trial-subsection, visual feedback was presented with instructions to respond faster if error rates were below $30 \%$ or to reduce speed if error rates were above $30 \%$. If a participant failed to respond to at least one stimulus, one additional 17-trial-subsection was added automatically. Attention level was monitored throughout the experiment by visual inspection (video camera).

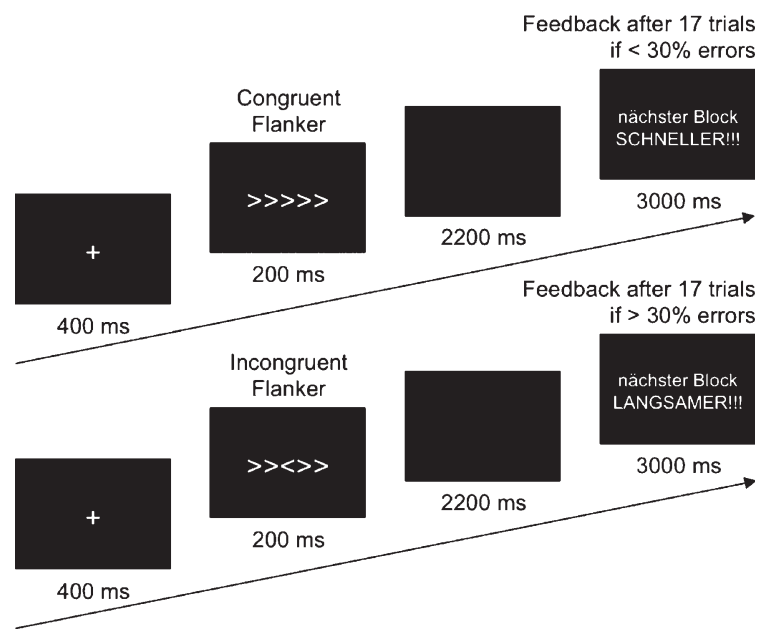

Fig. 1. Experimental design of the adapted Eriksen Flanker task. Participants were asked to indicate the direction of the middle arrowhead by pressing the left (index finger, right hand) or right (middle finger, right hand) mouse button. After each 17-trial-subsection, a visual feedback was presented saying "nächster Block SCHNELLER!!!" (go faster in the next section) or "nächster Block LANGSAMER!!!" (go slower in the next section) to provide sufficient error rates (272 stimuli; trial duration $=3000 \mathrm{~ms}$; feedback duration $=3000 \mathrm{~ms}$ ).

\section{EEG acquisition}

EEG was recorded using a high-density 256-channel HydroCelTM Geodesic Sensor Net (HCGSN; Electrical Geodesics, Inc.; EGI; Eugene, Oregon, USA) with $\mathrm{Cz}$ as reference electrode. Continuous data were recorded with a sampling rate of $250 \mathrm{~Hz}$ with $0.1 \mathrm{~Hz}$ high-pass and $100 \mathrm{~Hz}$ low-pass hardware filter. All electrode impedances were kept below $50 \mathrm{k} \Omega$ before starting the experiment, as recommended for the applied amplifier by EGI acquisition guidelines. 


\section{ERP analysis}

Data preprocessing and artifact rejection (amplitudes $>120 \mu \mathrm{V}$ ) was performed with BESA 5.3 software (Brain Electrical Source Analysis, Graefeling, Germany). After visual inspection, artifactcontaminated single channels were conservatively interpolated (range 0-5\%) using spherical spline interpolation [79]. Eye movement artifacts were removed using the multiple source approach by Berg and Scherg [80], and data were offline re-referenced to original average reference. We aimed at a minimum of six remaining errors after full artifact correction (see [81, 82]). Only two older controls had less than eight errors (6 and 7) after artifact correction (the number of erroneous and correct trials included into analysis after artifact correction for each group are given in Supplementary Table 1; available online: http://www.j-alz.com/issues/35/vol353.html\#supplementarydata06). Data were filtered from $0.1 \mathrm{~Hz}$ (6 dB/octave, forward) to $30 \mathrm{~Hz}(12 \mathrm{~dB} /$ octave, zero phase) for artifact rejection and high-pass filtered with $0.1 \mathrm{~Hz}$ ( $6 \mathrm{~dB} /$ octave, forward) for averaging. Response-locked averages were computed for erroneous and correct responses and filtered $0.1-15 \mathrm{~Hz}$ (baseline -200 to $-100 \mathrm{~ms}$ ). ERN and CRN were defined as the maximum negative peak at midline electrodes $\mathrm{Fz}, \mathrm{FCz}, \mathrm{Cz}$, and $\mathrm{PCz}(0-130 \mathrm{~ms}$ after button press; $15 \mathrm{~Hz}$ low-pass filter, $24 \mathrm{~dB}$ /octave, zero phase). Additionally, the error minus correct difference waveform was computed. Grand averages were computed for each group by averaging all individual waveforms.

\section{Behavioral data}

RT and error rates were measured and analyzed. Individual trials with RT shorter than $100 \mathrm{~ms}$ and longer than $2400 \mathrm{~ms}$ were excluded from further analyses. No participant exceeded $40 \%$ error rate.

\section{Statistical analysis}

Data analysis was performed with $\mathrm{R}$ statistical software package of The $\mathrm{R}$ Foundation of Statistical Computing (http://www.r-project.org; version 2.11.1 for Mac OS X, GUI 1.34 Leopard). Group comparisons for age, years of education, and cognitive performance were conducted with univariate analysis of variance (ANOVA) models. Group differences in gender distribution were assessed by Pearson's Chi-squared $\chi^{2}$ ) tests. Mixed effects ANOVA models with a random intercept for participants were cal- culated in order to analyze the behavioral data of the Flanker RT task and the ERP data while taking repeated measurements into account (package nlme for R [83]). Mixed effects ANOVAs for the behavioral data were conducted with Accuracy (RT of erroneous versus correct responses) $\times$ Condition (congruent versus incongruent) $\times$ Group for RTs and with Condition (congruent versus incongruent trials) $\times$ Group for error rates. Mixed effects ANOVAs for the ERN and CRN were conducted with Electrode site $\times$ ERP $($ ERN versus CRN) $\times$ Group for the ERP amplitudes and with ERP $(E R N$ versus $C R N) \times$ Group for ERP latencies. A mixed effects ANOVA for the error minus correct difference waveform's amplitude with Electrode site $\times$ Group and an ANOVA for group differences in the difference waveform's latency were calculated separately. Post-hoc tests were performed by lower order ANOVAs and $t$-tests (two-tailed), applying Tukey's honestly significant differences (Tukey HSD) test for multiple comparisons. Associations between ERP components, age, years of education, and neuropsychological test scores were further investigated across groups using the Pearson's $r$ product moment correlation coefficient. Normality assumptions of ANOVA models' residuals were tested using the Shapiro-Wilk normality test. However, since the Shapiro-Wilk test can be less accurate in smaller group sizes, residuals were further visually inspected by density and quantilequantile plots. All tests for statistical significance were applied with alpha $(\alpha) \leq 0.05$. $p$-values of multiple correlation coefficients were adjusted according to Holm's sequential rejection algorithm [84].

\section{RESULTS}

\section{Behavioral Data}

\section{Reaction time (RT)}

RTs are shown in Table 1 and Fig. 2a-b. A mixed effects ANOVA of Accuracy $\times$ Condition $\times$ Group revealed a main effect for Accuracy $\left(F_{(1,120)}=35.23\right.$, $p<0.0001)$ as well as an interaction of Condition $\times$ Group $\left(F_{(2,120)}=5.79, p=0.004\right)$. RTs were shorter for erroneous compared to correct responses $\left(t_{(90)}=-2.81, p=0.005\right)$, however, there was no significant interaction. As indicated by the Condition $\times$ Group interaction, younger controls performed faster in both stimulus conditions compared to older controls (congruent: $t_{(30)}=-4.67, p<0.0001$; incongruent: $\left.t_{(30)}=-3.80, p<0.001\right)$ and MCI subjects (congruent: $t_{(28)}=-6.48, p<0.0001$; incongruent: $\left.t_{(28)}=-7.19, p<0.0001\right)$. However, older controls 

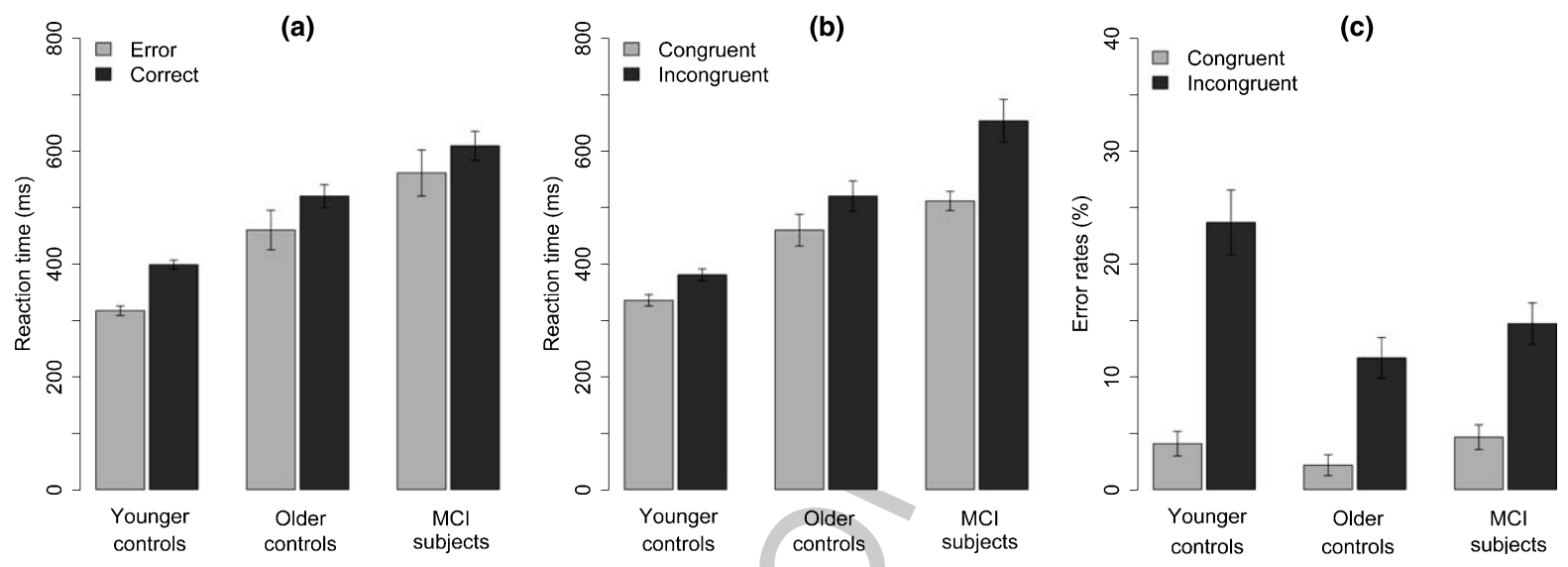

Fig. 2. Mean reaction times of younger adult controls, older adult controls and MCI subjects for (a) correct (Correct) and erroneous (Error) trials and for (b) congruent versus incongruent trials. (c) Mean error rates for congruent and incongruent trials. Error bars represent standard errors of the mean.

performed faster than MCI subjects only in the incongruent condition $\left(t_{(28)}=-3.51, p=0.002\right)$ but showed similar RTs in the congruent condition.

\section{Error rates}

Error rates are shown in Table 1 and Fig. 2c. A mixed effects ANOVA of Condition $\times$ Group revealed an interaction of Condition $\times$ Group $\left(F_{(2,43)}=9.39\right.$, $p<0.0001)$. Error rates were higher in incongruent compared to congruent trials in younger controls $\left(t_{(30)}=6.39, p<0.0001\right)$, older controls $\left(t_{(30)}=4.68\right.$, $p<0.0001)$ and MCI subjects $\left(t_{(26)}=4.71, p<0.0001\right)$. Furthermore, as indicated by the Condition $\times$ Group interaction, younger controls committed more errors than healthy older controls $\left(t_{(30)}=3.84, p=0.001\right)$ and MCI subjects $\left(t_{(28)}=2.77, p=0.02\right)$ in incongruent trials. Error rates did not differ between older controls and MCI subjects in incongruent trials. There were no group differences for congruent trials.

\section{ERP Data}

Grand averages of response-locked ERP waveforms for correct and erroneous trials as well as for the difference waveform are shown in Fig. 3. The calculation of the ERPs involved more correct than incorrect trials. Amplitudes for each group are shown in Fig. 4.

\section{ERN and CRN}

A mixed effects ANOVA of Electrode site $\times \mathrm{ERP} \times$ Group revealed interactions of Electrode site $\times \operatorname{ERP}\left(\mathrm{F}_{(3,301)}=3.80, p=0.01\right)$, Electrode site $\times$ Group $\left(F_{(6,301)}=4.74, p=0.0001\right)$ and ERP $\times$ Group $\left(F_{(2,301)}=8.76, p=0.0002\right)$. The negativity following errors was significantly larger than the negativity following correct responses across groups $\left(t_{(90)}=-7.53\right.$, $p<0.0001)$. The ERN was most negatively pronounced at electrodes $\mathrm{Fz}, \mathrm{FCz}$, and $\mathrm{Cz}$ but less at $\mathrm{PCz}(\mathrm{PCz}$ versus $\mathrm{Fz} / \mathrm{FCZ} / \mathrm{Cz}$ : all $\left.t_{(90)}>5, p<0.0001\right)$. In contrast, the $\mathrm{CRN}$ was most negatively pronounced at $\mathrm{Fz}$ and $\mathrm{FCz}$ but less at $\mathrm{Cz}$ and $\mathrm{PCz}(\mathrm{PCz} / \mathrm{Cz}$ versus $\mathrm{Fz} / \mathrm{FCz}$ : all $\left.t_{(90)}>3, p<0.01\right)$. In the young control group, no CRN could be observed (i.e., the CRN amplitude was not different from zero). There was no difference between groups in ERN amplitude $\left(F_{(2,181)}=0.73, p=0.48\right)$. However, the CRN was more negatively pronounced in MCI subjects compared to younger $\left(t_{(28)}=-3.02\right.$, $p=0.008)$ and older controls $\left(t_{(28)}=-2.50, p=0.04\right)$. There was no difference in CRN amplitude between both control groups. The mean latency of the ERN was $36.8 \mathrm{~ms}(S D=25.2 \mathrm{~ms})$ for younger controls, $50.9 \mathrm{~ms}(S D=26.0 \mathrm{~ms})$ for older controls and $43.7 \mathrm{~ms}$ $(S D=39.6 \mathrm{~ms})$ for MCI subjects. Latencies of the CRN were on average $47.8 \mathrm{~ms}(S D=52.3 \mathrm{~ms})$ for younger controls, $45.3 \mathrm{~ms}(S D=24.4 \mathrm{~ms})$ for older controls and $40.0 \mathrm{~ms}(S D=32.4 \mathrm{~ms})$ for MCI subjects. There was no main effect or interaction for ERN or CRN latency.

\section{Error minus correct difference waveform (Error-Correct)}

A mixed effects ANOVA of Electrode site $\times$ Group revealed main effects for Electrode site $\left(F_{(3,129)}=10.73, \quad p<0.0001\right) \quad$ and Group $\left(F_{(2,43)}=5.47, \quad p=0.008\right)$. The Electrode site $\times$ Group interaction narrowly missed significance $\left(F_{(6,129)}=2.05, \quad p=0.06\right)$. A negative difference waveform could be observed at all four electrodes 

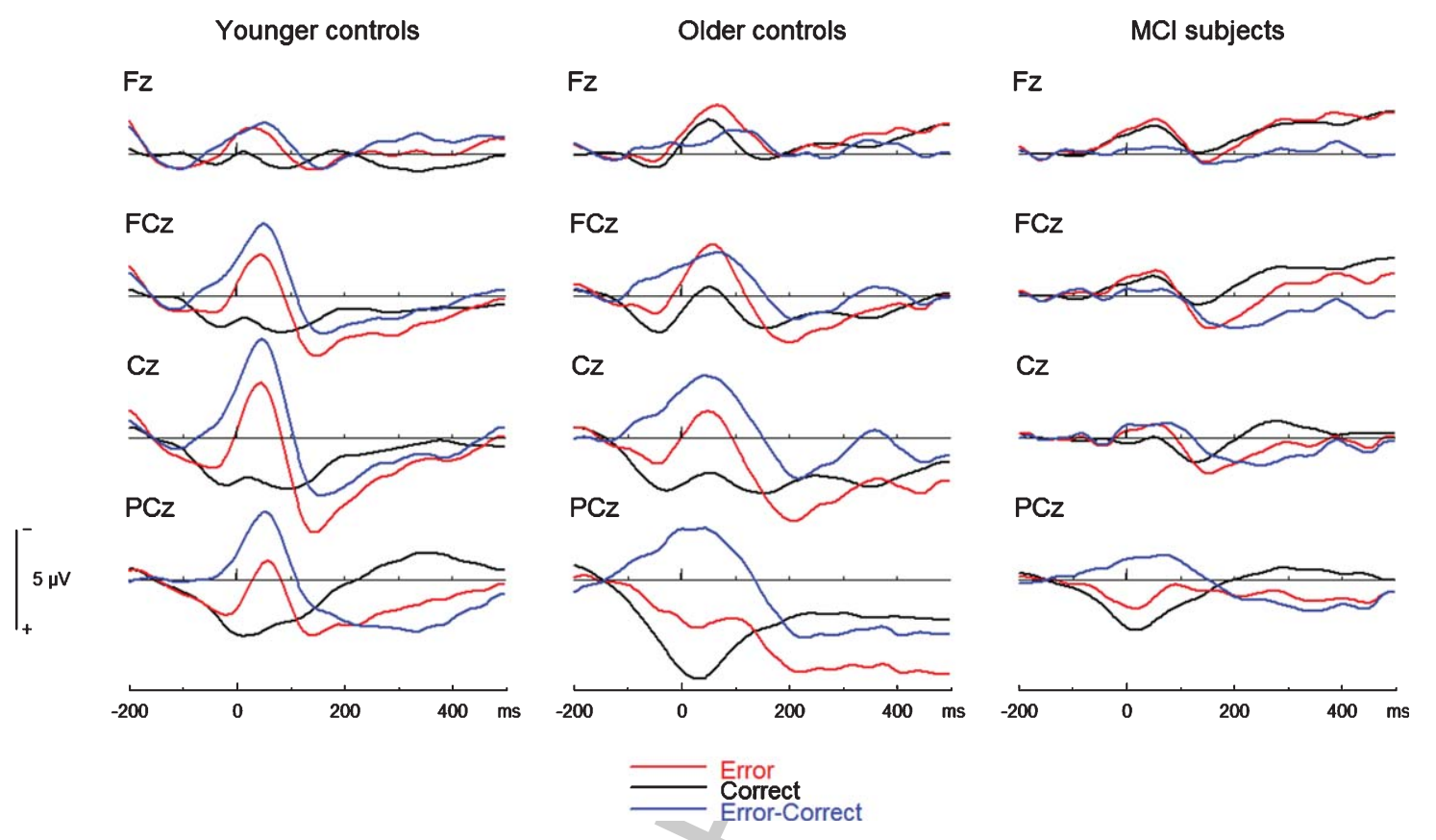

Fig. 3. Response-locked waveforms for correct responses (Correct), erroneous responses (Error) and the error minus correct difference waveform (Error-Correct) of younger adult controls, older adult controls and $\mathrm{MCI}$ subjects at electrodes Fz, FCz, Cz, and PCz (time window $=-200-500 \mathrm{~ms}$; button press $=0 \mathrm{~ms}$; negative up).

(most negative amplitudes at $\mathrm{Cz}$ ) and was smaller (i.e., less negative) in MCI subjects compared to younger $\left(t_{(28)}=5.02, p<0.0001\right)$ and older controls $\left.t_{(28)}=3.57, p=0.001\right)$. There was no difference in the Error-Correct waveform's amplitude between younger and older controls. The mean latency of the difference waveform was $46.5 \mathrm{~ms}(S D=26.2 \mathrm{~ms})$ for younger controls, $66.8 \mathrm{~ms}(S D=37.5 \mathrm{~ms})$ for older controls and $50.0 \mathrm{~ms}(S D=36.3 \mathrm{~ms})$ for MCI subjects. However, the difference waveform's latency did not differ between groups.

\section{Associations between ERP Data and Performance in Tests of Executive Function}

Pearson's $r$ correlation coefficient was calculated across older participants $(n=30)$ for ERP amplitudes (at electrodes $\mathrm{Fz}, \mathrm{FCz}, \mathrm{Cz}$, and $\mathrm{PCz}$ ) and cognitive test performances in tests measuring executive function (i.e., digit span test, digit-symbol test, TMT-A/B, and verbal fluency test). There was no correlation of the ERN amplitude with any of the cognitive test scores. However, after alpha correction for multiple correlation coefficients according to Holm [84], cognitive performances in the TMT-B and the verbal fluency test were correlated with the CRN amplitude (TMT-B: $r=-0.51, p=0.004$; verbal fluency: $r=0.46$, $p=0.01)$ and with the difference waveform's amplitude (TMT-B: $r=0.44, p=0.01$; verbal fluency: $r=-0.50$, $p=0.005)$. These correlations indicate that smaller CRN amplitudes and larger Error-Correct differences were associated with better performance in tests of executive function (Fig. 5).

\section{DISCUSSION}

This study investigated electrophysiological correlates of executive functions, more precisely of performance monitoring (ERN and CRN) in younger and older adults compared to older adults with clinical MCI syndrome. We found that MCI is associated with an increase in CRN amplitudes compared to younger and older adult controls, but no group difference was observed in the ERN component. Consistent with our initial assumption, MCI subjects showed reduced differentiation between ERN and CRN amplitudes (i.e., reduced Error-Correct difference waveforms) and demonstrated overall worse behavioral task performance compared to both younger and older adult controls. In contrast to older controls, MCI subjects failed to show the accuracy over speed preference as it is normally observed in the older adults [48, 51]. Furthermore, older controls showed overall RT slowing but no alterations in the ERN or CRN compared 


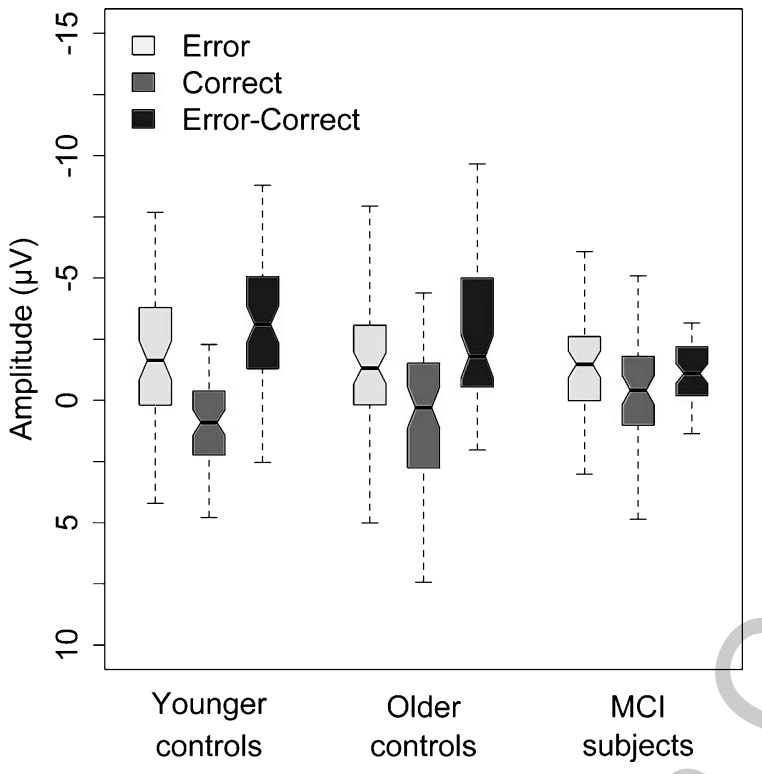

Fig. 4. Boxplots for the peak amplitudes of the responselocked waveforms for correct responses (Correct), erroneous responses (Error) and the error minus correct difference waveform (Error-Correct) of younger adult controls, older adult controls and MCI subjects at electrodes $\mathrm{Fz}, \mathrm{FCz}, \mathrm{Cz}$, and $\mathrm{PCz}$.

to younger controls. Most interestingly and consistent with our third hypothesis, both the CRN and the difference waveform were significantly correlated with the performance in cognitive tests demanding executive control and inhibition, i.e., the verbal fluency test and the TMT-B. These tests also discriminated between normal age-related decline and $\mathrm{MCI}$ in our sample. We postulate that error processing (during easy tasks) remains intact during healthy aging. However, as older adults move along the continuum from normal aging to $\mathrm{MCI}$ (and later in life possibly further to $\mathrm{AD}$; see e.g., [30]), performance monitoring becomes less specific (as indicated by reduced Error-Correct difference waveforms), which might reflect early pathological aging.

Consistent with previous studies, all participants showed larger electrophysiological negativities after erroneous compared to correct trials at fronto-central electrodes with controls showing no or only very small negativities following correct responses (e.g., [55, 61], see also [44]). The relationship of both ERN and $\mathrm{CRN}$, as reflected in the error minus correct difference waveform, was attenuated in MCI subjects but was constant in younger and older adult controls. This effect was previously reported in AD patients [58] but had not been investigated in studies with MCI subjects before.
As a correlate of error detection, the ERN reflects detection of mismatches between response errors and required (correct) responses [34, 44, 45] and can most likely be observed after premature responses, so-called "slips" [41, 45]. The CRN, in contrast, presumably plays a more general role in performance monitoring $[35,50]$. It likely reflects error processing or uncertainty during correct trials [33, 34]. We observed no differences in ERN amplitude or latency between groups. These results are consistent with previous studies applying different tasks to investigate the impact of normal aging on the ERN component ([61]; see also $[63,64])$ but contradict earlier studies applying a similar Flanker RT task in healthy subjects that showed an age-related attenuation of the ERN in healthy older compared to younger controls [53-55]. One possible explanation might be related to methodological differences: The respective studies [53-55] applied a Flanker paradigm to investigate age differences in performance monitoring and error detection during premature (or speeded) incorrect responses. Target and flanker stimuli were not presented simultaneously as in our study. Instead, the central arrowhead was preceded by the flankers by $100 \mathrm{~ms}$, which might have reduced postresponse ambiguity (i.e., post-response conflict) due to a decreased activation of the correct response and enhanced premature motor activity $[85,86]$. In line with this assumption, Falkenstein et al. [53] reported no age-related differences in the CRN (but see [55]) but all the three studies showed a reduced ERN in older compared to younger adults. In an earlier study, Maier et al. [87] concluded that increased allocation of attention to the flankers (as in [53-55]) reduces response conflict and error detection, which might be reflected in a reduced ERN. This was not investigated in our study but as the studies of Falkenstein et al. [53], Hoffmann \& Falkenstein [54], and Schreiber et al. [55] indicate, this effect might be more pronounced in older age. Inconsistencies in age-related alterations in the ERN (and $\mathrm{CRN}$ ) component might further be related to differences in exclusionary criteria for older adult controls. In contrast to our study, most of the previous studies investigating ERN in young compared to older adults either did not thoroughly examine cognitive functions or did not report whether older adults with probable MCI were excluded [36, 51, 53-57].

The literature about age effects on the $\mathrm{CRN}$ is limited and conflicting [55, 58,61]. Consistent with a previous study [53], we found no differences in CRN amplitude or latency in older adults without MCI compared to younger adult controls. Furthermore, studies with clinical samples suggested that the CRN is a marker of 
(a)

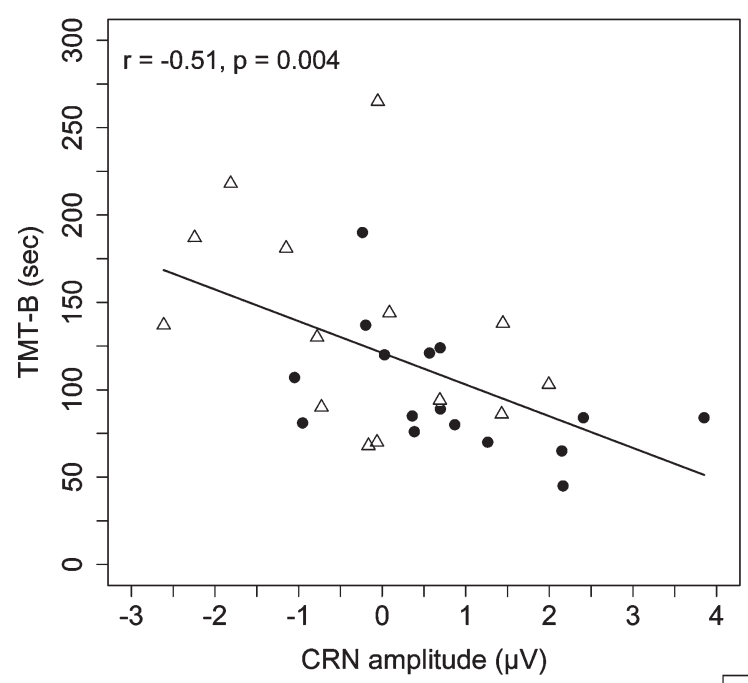

(c)

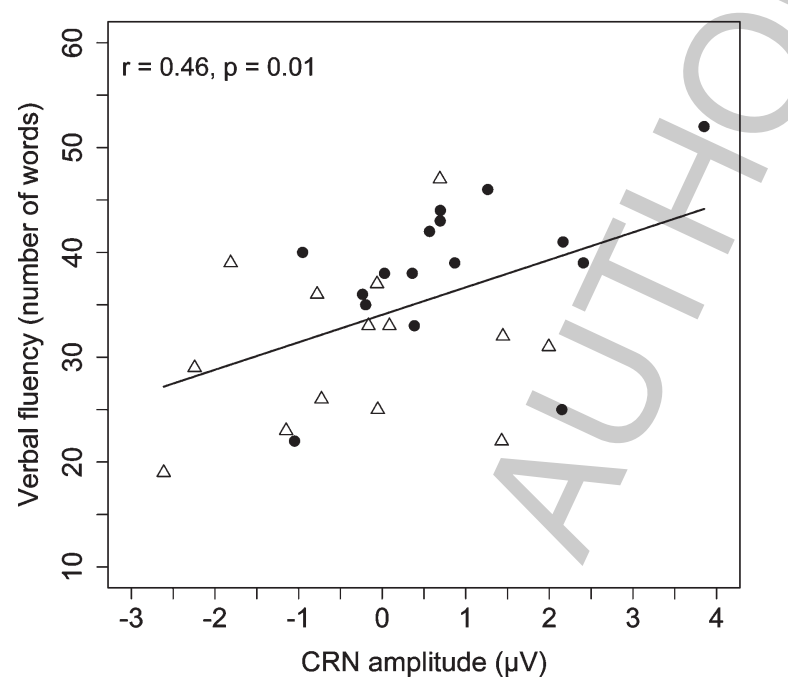

(b)

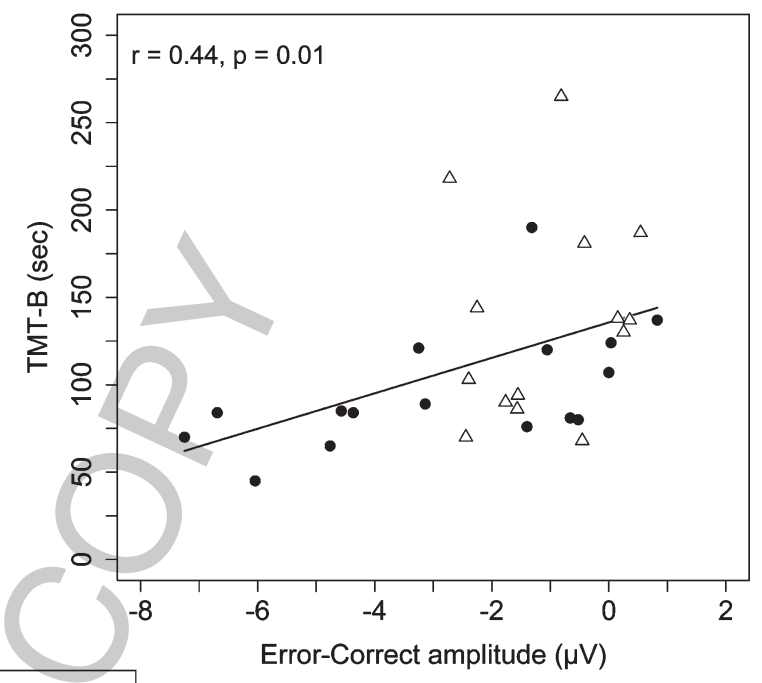

(d)

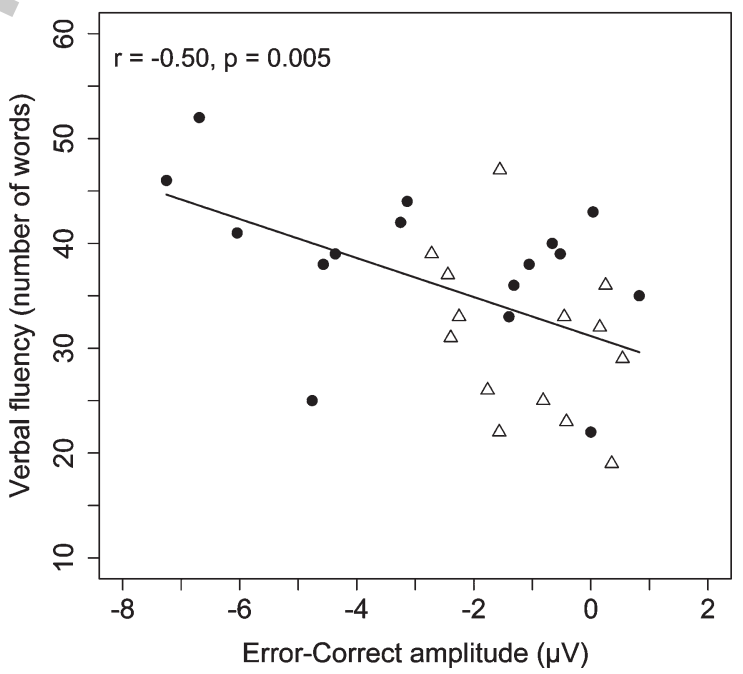

Fig. 5. Correlation of the CRN amplitude (left) and the error minus correct (Error-Correct) difference waveform's amplitude (right) at electrodes $\mathrm{Fz}, \mathrm{FCz}, \mathrm{Cz}$, and PCz with Trail Making Test (TMT) B (a and b) and verbal fluency (c and d) in older participants ( $n=30)$.

(pathology-related) alterations in performance monitoring and cognition in general $[66,88]$. The significant increase in CRN amplitude in MCI subjects compared to both control groups could be related to various factors: The CRN can be induced by response ambiguity (i.e., uncertainty) but also by stimulus misperception or speed over accuracy instructions [44, 45, 48, 49]. We assume that the latter two factors did not contribute significantly to the reported differences in CRN amplitude between MCI subjects and controls: (i) Stimulus misperception was minimized since our experimental task was rather simple, with moderate stimulus duration $(200 \mathrm{~ms})$ and training sessions to consolidate the relevant S-R associations (training sessions were not included in the ERP analysis). The subjects' vision was normal or corrected to normal. (ii) The task instruction focused on both speed and accuracy. Feedback during the task induced time pressure. However, since the response deadline was rather long $(2200 \mathrm{~ms})$ and feedback was only presented after each subsection 
of 17 trials, we assume that the feedback did not affect MCI subjects significantly more than controls. However, since target and flankers were presented simultaneously, we assume that the reported increase in CRN amplitudes in MCI is mainly related to simultaneous co-activation of the correct and incorrect responses (i.e., uncertainty) and the resulting increase in mismatch detection demands [89, 90]. This assumption is consistent with the literature reporting that stronger representation of the incorrect compared to the correct response (i.e., sub-threshold co-activation of the incorrect response during correct reactions) can lead to increased CRN amplitudes $[44,91]$ and, hence, to decreased Error-Correct differences as we observed in MCI subjects. This is further supported by Shackman et al. [92] who concluded that the cingulate cortex (more specifically, the aMCC) integrates negative affect during responses (e.g., uncertainty), possible (negative) response outcomes (e.g., errors), and cognitive control (e.g., to resolve uncertainty or response conflict).

Our ERP and behavioral data indicate that uncertainty remained high in MCI subjects compared to both younger and older adult controls throughout the experiment. One possible explanation could be that MCI subjects have lower cognitive control, leading to less efficient inhibition of the flanker stimuli (i.e., to worse speed and accuracy performances). The increase in CRN amplitude, as observed in our study, might reflect this performance monitoring deficit in MCI subjects. In contrast, the preserved dissociation between ERN and CRN (i.e., unchanged Error-Correct difference) in healthy older compared to younger adults might indicate that older adults without MCI still have sufficient inhibitory ability during easy response conflict tasks ([93], see also [54]). This idea is supported by the literature, indicating that although inhibition becomes more difficult with increasing age [51, 52], it conspicuously deteriorates in MCI and early AD [94, 95]. In daily life of MCI subjects, a performance monitoring deficit might presumably lead to inefficient correction of action strategies despite otherwise intact overall daily functioning. This is further supported by recent studies reporting impairments in complex activities of daily living in older adults with MCI compared to agematched controls [96, 97].

\section{CONCLUSION}

First, our results indicate that MCI is associated with less specific performance monitoring as reflected in a failure of electrophysiological differentiation following erroneous versus correct behavioral responses (i.e., reduced Error-Correct difference waveforms). For the older participants of both the MCI and the older control group, the Error-Correct difference was significantly correlated with cognitive test performance demanding high executive control and inhibition. Second, our findings support the growing evidence that ERN and CRN are distinct components reflecting error-specific versus overall performance monitoring, respectively $[50,55,58,61$, 98]. Finally, ERN and CRN are differentially affected by healthy aging compared to MCI. These results might be of interest for future studies investigating frontal dysfunction in MCI.

\section{ACKNOWLEDGMENTS}

This research was carried out at the University of Konstanz, Germany, and was funded by the WINKolleg (Junior Academy for Young Scholars and Scientists) of the Heidelberg Academy of Sciences and Humanities, Germany. Furthermore, ITK is a fellow of the Zukunftskolleg (now alumna) of the University of Konstanz, Germany, which also provided support for this project, and is now at the University of Ulm. FT is now a member of the TU Dresden, Germany. We want to thank Anne Korzowski and Daria Laptinskaya for their support in data acquisition.

Authors' disclosures available online (http://www.jalz.com/disclosures/view.php?id=1672).

\section{REFERENCES}

[1] Raz N, Williamson A, Gunning-Dixon F, Head D, Acker JD (2000) Neuroanatomical and cognitive correlates of adult age differences in acquisition of a perceptual-motor skill. Microsc Res Tech 51, 85-93.

[2] Resnick SM, Pham DL, Kraut MA, Zonderman AB, Davatzikos C (2003) Longitudinal magnetic resonance imaging studies of older adults: A shrinking brain. J Neurosci $\mathbf{2 3}$, 3295-3301.

[3] Baudouin A, Clarys D, Vanneste S, Isingrini M (2009) Executive functioning and processing speed in age-related differences in memory: Contribution of a coding task. Brain Cogn 71, 240-245.

[4] Braver TS, Barch DM (2002) A theory of cognitive control, aging cognition, and neuromodulation. Neurosci Biobehav Rev 26, 809-817.

[5] Rabbitt P (2005) Frontal brain chances and cognitive performance in old age. Cortex 41, 238-240.

[6] West RL (1996) An application of prefrontal cortex function theory to cognitive aging. Psychol Bull 120, 272-292.

[7] West R, Schwarb H (2006) The influence of aging and frontal function on the neural correlates of regulative and evaluative aspects of cognitive control. Neuropsychology 20, 468-481. 
[8] Salthouse TA, Hancock HE, Meinz EJ, Hambrick DZ (1996) Interrelations of age, visual acuity, and cognitive functioning. J Gerontol B Psychol Sci Soc Sci 51, P317-P330.

[9] Keys BA, White DA (2000) Exploring the relationship between age, executive abilities, and psychomotor speed. $J$ Int Neuropsychol Soc 6, 76-82.

[10] Gladsjo JA, Schuman CC, Evans JD, Peavy GM, Miller SW, Heaton RK (1999) Norms for letter and category fluency: Demographic corrections for age, education, and ethnicity. Assessment 6, 147-178.

[11] Troyer AK (2000) Normative data for clustering and switching on verbal fluency tasks. J Clin Exp Neuropsychol 22, 370-378.

[12] Rabbitt P (1966) Error correction time without external error signals. Nature 212, 438.

[13] Salthouse TA, Atkinson TM, Berish DE (2003) Executive functioning as a potential mediator of age-related cognitive decline in normal adults. J Exp Psychol Gen 132, 566-594.

[14] Crawford J, Bryan J, Luszcz M, Obonsawin M, Stewart L (2000) The executive decline hypothesis of cognitive aging: Do executive deficits qualify as differential deficits and do they mediate age-related memory decline? Neuropsychol Dev Cogn B Aging Neuropsychol Cogn 7, 9-31.

[15] Taconnat L, Clarys D, Vanneste S, Bouazzaoui B, Isingrini M (2007) Aging and strategic retrieval in a cued-recall test: The role of executive functions and fluid intelligence. Brain Cogn 64, 1-6.

[16] Troyer AK, Graves RE, Cullum CM (1994) Executive functioning as a mediator of the relationship between age and episodic memory in healthy aging. Neuropsychol Dev Cogn B Aging Neuropsychol Cogn 1, 45-53.

[17] Busse A, Bischkopf J, Riedel-Heller SG, Angermeyer MC (2003) Subclassifications for mild cognitive impairment: Prevalence and predictive validity. Psychol Med 33, 10291038.

[18] Petersen RC, Smith GE, Waring SC, Ivnik RJ, Tangalos EG, Kokmen E (1999) Mild cognitive impairment: Clinical characterization and outcome. Arch Neurol 56, 303-308.

[19] Winblad B, Palmer K, Kivipelto M, Jelic V, Fratiglioni L, Wahlund L-O, Nordberg A, Bäckman L, Albert M, Almkvist O, Arai H, Basun H, Blennow K, De Leon M, DeCarli C, Erkinjuntti T, Giacobini E, Graff C, Hardy J, Jack C, Jorm A, Ritchie K, Van Duijn C, Visser P, Petersen RC (2004) Mild cognitive impairment - beyond controversies, towards a consensus: Report of the International Working Group on Mild Cognitive Impairment. J Intern Med 256, 240-246.

[20] Jack CR, Lowe VJ, Senjem ML, Weigand SD, Kemp BJ, Shiung MM, Knopman DS, Boeve BF, Klunk WE, Mathis CA, Petersen RC (2008) 11C PiB and structural MRI provide complementary information in imaging of Alzheimer's disease and amnestic mild cognitive impairment. Brain $\mathbf{1 3 1}$ 665-680.

[21] Petersen RC, Parisi JE, Dickson DW, Johnson KA, Knopman DS, Boeve BF, Jicha GA, Ivnik RJ, Smith GE, Tangalos EG, Braak H, Kokmen E (2006) Neuropathologic features of amnestic mild cognitive impairment. Arch Neurol 63, 665672.

[22] Stephan BCM, Hunter S, Harris D, Llewellyn DJ, Siervo M, Matthews FE, Brayne C (2012) The neuropathological profile of mild cognitive impairment (MCI): A systematic review. Mol Psychiatry 17, 1056-1076.

[23] Lo RY, Hubbard AE, Shaw LM, Trojanowski JQ, Petersen RC, Aisen PS, Weiner MW, Jagust WJ (2011) Longitudinal change of biomarkers in cognitive decline. Arch Neurol $\mathbf{6 8}$ 1257-1266.
[24] Anchisi D, Borroni B, Franceschi M, Kerrouche N, Kalbe E, Beuthien-Beumann B, Cappa S, Lenz O, Ludecke S, Marcone A, Mielke R, Ortelli P, Padovani A, Pelati O, Pupi A, Scarpini E, Weisenbach S, Herholz K, Salmon E, Holthoff V, Sorbi S, Fazio F, Perani D (2005) Heterogeneity of brain glucose metabolism in mild cognitive impairment and clinical progression to Alzheimer disease. Arch Neurol 62, 1728-1733.

[25] Bouwman FH, Schoonenboom SNM, Van der Flier WM, Van Elk EJ, Kok A, Barkhof F, Blankenstein MA, Scheltens P (2007) CSF biomarkers and medial temporal lobe atrophy predict dementia in mild cognitive impairment. Neurobiol Aging 28, 1070-1074.

[26] De Leon MJ, DeSanti S, Zinkowski R, Mehta PD, Pratico D, Segal S, Rusinek H, Li J, Tsui W, Saint Louis LA, Clark CM, Tarshish C, Li Y, Lair L, Javier E, Rich K, Lesbre P, Mosconi L, Reisberg B, Sadowski M, DeBernadis JF, Kerkman DJ, Hampel H, Wahlund L-O, Davies P (2006) Longitudinal CSF and MRI biomarkers improve the diagnosis of mild cognitive impairment. Neurobiol Aging 27, 394-401.

[27] Hansson O, Zetterberg H, Buchhave P, Londos E, Blennow K, Minthon L (2006) Association between CSF biomarkers and incipient Alzheimer's disease in patients with mild cognitive impairment: A follow-up study. Lancet Neurol 5, 228-234.

[28] Landau SM, Harvey D, Madison CM, Koeppe RA, Reiman EM, Foster NL, Weiner MW, Jagust WJ (2011) Associations between cognitive, functional, and FDG-PET measures of decline in AD and MCI. Neurobiol Aging 32, 1207-1218.

[29] Mattsson N, Zetterberg H, Hansson O, Andreasen N, Parnetti L, Jonsson M, Herukka S-K, Van der Flier WM, Blankenstein MA, Ewers M, Rich K, Kaiser E, Verbeek M, Tsolaki M, Mulugeta E, Rosén E, Aarsland D, Visser PJ, Schröder J, Marcusson J, De Leon M, Hampel H, Scheltens P, Pirttilä T, Wallin A, Jönhagen ME, Minthon L, Winblad B, Blennow $\mathrm{K}$ (2009) CSF biomarkers and incipient Alzheimer disease in patients with mild cognitive impairment. JAMA 302, 385-393.

[30] Sperling RA, Aisen PS, Beckett LA, Bennett DA, Craft S, Fagan AM, Iwatsubo T, Jack CR, Kaye J, Montine TJ, Park DC, Reiman EM, Rowe CC, Siemers E, Stern Y, Yaffe K, Carrillo MC, Thies B, Morrison-Bogorad M, Wagster MV, Phelps CH (2011) Toward defining the preclinical stages of Alzheimer's disease: Recommendations from the National Institute on Aging-Alzheimer's Association workgroups on diagnostic guidelines for Alzheimer's disease. Alzheimers Dement 7, 280-292.

[31] Albert MS, DeKosky ST, Dickson D, Dubois B, Feldman HH, Fox NC, Gamst A, Holtzman DM, Jagust WJ, Petersen RC, Snyder PJ, Carrillo MC, Thies B, Phelps CH (2011) The diagnosis of mild cognitive impairment due to Alzheimer's disease: Recommendations from the National Institute on Aging-Alzheimer's Association workgroups on diagnostic guidelines for Alzheimer's disease. Alzheimers Dement 7, 270-279.

[32] Gauthier S, Patterson C, Gordon M, Soucy J-P, Schubert F, Leuzy A (2011) Commentary on "Recommendations from the National Institute on Aging-Alzheimer's Association workgroups on diagnostic guidelines for Alzheimer's disease." A Canadian perspective. Alzheimers Dement 7, 330-232.

[33] Gehring WJ, Goss B, Coles MGH, Meyer DE, Donchin E (1993) A neural system for error detection and compensation. Psychol Sci 4, 385-390.

[34] Falkenstein M, Hohnsbein J, Hoormann J, Blanke L (1991) Effects of crossmodal divided attention on late ERP components. II. Error processing in choice reaction tasks. Electroencephalog Clin Neurophysiol 78, 447-455. 
[35] Falkenstein M, Hoormann J, Christ S, Hohnsbein J (2000) ERP components on reaction errors and their functional significance: A tutorial. Biol Psychol 51, 87-107.

[36] Gehring WJ, Knight RT (2000) Prefrontal-cingulate interactions in action monitoring. Nat Neurosci 3, 516-520.

[37] Hajcak G, Moser JS, Yeung N, Simons RF (2005) On the ERN and the significance of errors. Psychophysiology 42, 151-160.

[38] Holroyd CB, Coles MGH (2002) The neural basis of human error processing: Reinforcement learning, dopamine, and the error-related negativity. Psychol Rev 109, 679-709.

[39] Botvinick MM, Cohen JD, Carter CS (2004) Conflict monitoring and anterior cingulate cortex: An update. Trends Cogn Sci 8, 539-546.

[40] Debener S, Ullsperger M, Siegel M, Fiehler K, Von Cramon DY, Engel AK (2005) Trial-by-trial coupling of concurrent electroencephalogram and functional magnetic resonance imaging identifies the dynamics of performance monitoring. J Neurosci 25, 11730-11737.

[41] Dehaene S, Posner M, Tucker D (1994) Localization of a neural system for error detection and compensation. Psychol Sci 5, 303-306.

[42] Luu P, Flaisch T, Tucker DM (2000) Medial frontal cortex in action monitoring. J Neurosci 20, 464-469.

[43] Ridderinkhof KR, Ullsperger M, Crone EA, Nieuwenhuis $S$ (2004) The role of the medial frontal cortex in cognitive control. Science 306, 443-447.

[44] Coles MG, Scheffers MK, Holroyd CB (2001) Why is there an ERN/Ne on correct trials? Response representations, stimulus-related components, and the theory of error-processing. Biol Psychol 56, 173-189.

[45] Scheffers MK, Coles MGH (2000) Performance monitoring in a confusing world: Error-related brain activity, judgments of response accuracy, and types of errors. J Exp Psychol Hum Percept Perform 26, 141-151.

[46] Ford JM (1999) Schizophrenia: The broken P300 and beyond. Psychophysiology 36, 667-682.

[47] Vidal F, Hasbroucq T, Grapperon J, Bonnet M (2000) Is the error negativity" specific to errors? Biol Psychol 51, 109-128.

[48] Nieuwenhuis S, Ridderinkhof KR, Talsma D, Coles MGH, Holroyd CB, Kok A, Van der Molen MW (2002) A computational account of altered error processing in older age: Dopamine and the error-related negativity. Cogn Affect Behav Neurosci 2, 19-36.

[49] Pailing PE, Segalowitz SJ (2004) The effects of uncertainty in error monitoring on associated ERPs. Brain Cogn 56, 215233.

[50] Bartholow BD, Pearson MA, Dickter CL, Sher KJ, Fabiani M, Gratton G (2005) Strategic control and medial frontal negativity: Beyond errors and response conflict. Psychophysiology 42, 33-42.

[51] Band GP, Kok A (2000) Age effects on response monitoring in a mental-rotation task. Biol Psychol 51, 201-221.

[52] Eppinger B, Kray J, Mecklinger A, John O (2007) Age differences in task switching and response monitoring: Evidence from ERPs. Biol Psychol 75, 52-67.

[53] Falkenstein M, Hoormann J, Hohnsbein J (2001) Changes of error-related ERPs with age. Exp Brain Res 138, 258-262.

[54] Hoffmann S, Falkenstein M (2011) Aging and error processing: Age related increase in the variability of the error-negativity is not accompanied by increase in response variability. PLoS One 6, e17482.

[55] Schreiber M, Pietschmann M, Kathmann N, Endrass T (2011) ERP correlates of performance monitoring in elderly. Brain Cogn 76, 131-139.
[56] Themanson JR, Hillman CH, Curtin JJ (2006) Age and physical activity influences on action monitoring during task switching. Neurobiol Aging 27, 1335-1345.

[57] West R (2004) The effects of aging on controlled attention and conflict processing in the Stroop task. J Cogn Neurosci 16, 103-113.

[58] Mathalon D, Bennett A, Askari N, Gray E, Rosenbloom M, Ford J (2003) Response-monitoring dysfunction in aging and Alzheimer's disease: An event-related potential study. Neurobiol Aging 24, 675-685.

[59] Ito J, Kitagawa J (2005) Error processing in patients with Alzheimer's disease. Pathophysiology 12, 97-101.

[60] Ito J, Kitagawa J (2006) Performance monitoring and error processing during a lexical decision task in patients with Parkinson's disease. J Geriatr Psychiatry Neurol 19, 46-54.

[61] Eppinger B, Kray J, Mock B, Mecklinger A (2008) Better or worse than expected? Aging, learning, and the ERN. Neuropsychologia 46, 521-539.

[62] Pietschmann M, Endrass T, Czerwon B, Kathmann N (2011) Aging, probabilistic learning and performance monitoring. Biol Psychol 86, 74-82.

[63] Pietschmann M, Endrass T, Kathmann N (2011) Age-related alterations in performance monitoring during and after learning. Neurobiol Aging 32, 1320-1330.

[64] Pietschmann M, Simon K, Endrass T, Kathmann N (2008) Changes of performance monitoring with learning in older and younger adults. Psychophysiology 45, 559-568.

[65] Simons RF (2010) The way of our errors: Theme and variations. Psychophysiology 47, 1-14.

[66] Ullsperger M (2006) Performance monitoring in neurological and psychiatric patients. Int J Psychophysiol 59, 59-69.

[67] Eriksen B, Eriksen C (1974) Effects of noise letters upon the identification of a target letter in a nonsearch task. Percept Psychophys 16, 143-149.

[68] Oldfield RC (1971) The assessment and analysis of handedness: The Edinburgh inventory. Neuropsychologia 9, 97-113.

[69] Ackenheil M, Stotz-Ingenlath G, Dietz-Bauer R, Vossen A (1999) M.I.N.I. Mini Internationale Neuropsychiatric Interview (German version 5.0.0, DSM-IV), Psychiatric University Clinic, Munich.

[70] Geerlings MI, Jonker C, Bouter LM, Ader HJ, Schmand B (1999) Association between memory complaints and incident Alzheimer's disease in elderly people with normal baseline cognition. Am J Psychiatry 156, 531-537.

[71] Jorm AF, Christensen H, Korten AE, Henderson AS, Jacomb PA, Mackinnon A (1997) Do cognitive complaints either predict future cognitive decline or reflect past cognitive decline? A longitudinal study of an elderly community sample. Psychol Med 27, 91-98.

[72] McKhann G, Drachman D, Folstein M, Katzman R, Price D, Stadlan EM (1984) Clinical diagnosis of Alzheimer's disease: Report of the NINCDS-ADRDA Work Group under the auspices of Department of Health and Human Services Task Force on Alzheimer's Disease. Neurology 34, 939-944.

[73] American Psychiatric Association (2000) Diagnostic and statistical manual of mental disorders, Washington, DC.

[74] Gauggel S, Birkner B (1999) Validität und Reliabilität einer deutschen Version der Geriatrischen Depressionsskala (GDS) [Validity and reliability of a German version of the Geriatric Drepression Scale (GDS)]. Z Klin Psychol 28, 18-27.

[75] Yesavage JA, Brink TL, Rose TL, Lum O, Huang V, Adey M, Leirer VO (1982) Development and validation of a geriatric depression screening scale: A preliminary report. J Psychiatr Res 17, 37-49. 
[76] Folstein MF, Folstein SE, McHugh PR (1975) "Mini-mental state". A practical method for grading the cognitive state of patients for the clinician. J Psychiatr Res 12, 189-198.

[77] Welsh KA, Butters N, Mohs RC, Beekly D, Edland S, Fillenbaum G, Heyman A (1994) The Consortium to Establish a Registry for Alzheimer's Disease (CERAD). Part V. A normative study of the neuropsychological battery. Neurology 44, 609-614

[78] Tewes U. (1991) Hamburg-Wechsler-Intelligenztest fuür Erwachsene - rev. ed. (HAWIE-R), Huber, Bern, Stuttgart, Toronto.

[79] Perrin F, Pernier J, Bertrand O, Echallier JF (1989) Spherical splines for scalp potential and current density mapping. Electroencephalogr Clin Neurophysiol 72, 184-187.

[80] Berg P, Scherg M (1994) A multiple source approach to the correction of eye artifacts. Electroencephalogr Clin Neurophysiol 90, 229-241.

[81] Olvet DM, Hajcak G (2009) The stability of error-related brain activity with increasing trials. Psychophysiology 46, 957-961.

[82] Pontifex MB, Scudder MR, Brown ML, O'Leary KC, Wu C-T, Themanson JR, Hillman CH (2010) On the number of trials necessary for stabilization of error-related brain activity across the life span. Psychophysiology 47, 767-773.

[83] Pinheiro J, Bates D, DebRoy S, Sarkar D, the R Development Core Team (2011) nlme: Linear and nonlinear mixed effects models. R package version 3.1-101, http://cran.rproject.org/web/packages/nlme/citation.html, Last updated 2011, Accessed on 2011

[84] Holm S (1979) A simple sequentially rejective multiple test procedure. Scand J Statist 6, 65-70.

[85] Yeung N, Botvinick MM, Cohen JD (2004) The neural basis of error detection: Conflict monitoring and the error-related negativity. Psychol Rev 111, 931-959.

[86] Steinhauser M, Maier M, Hübner R (2008) Modeling behavioral measures of error detection in choice tasks: Response monitoring versus conflict monitoring. J Exp Psychol Hum Percept Perform 34, 158-176.

[87] Maier M, Steinhauser M, Hübner R (2008) Is the error-related negativity amplitude related to error detectability? Evidence from effects of different error types. J Cogn Neurosci 20, 2263-2273.

[88] Endrass T, Klawohn J, Schuster F, Kathmann N (2008) Overactive performance monitoring in obsessive-compulsive disorder: ERP evidence from correct and erroneous reactions. Neuropsychologia 46, 1877-1887.

[89] Coles MG, Gratton G, Bashore TR, Eriksen CW, Donchin E (1985) A psychophysiological investigation of the continuous flow model of human information processing. J Exp Psychol Hum Percept Perform 11, 529-553.

[90] Gratton G, Coles MG, Sirevaag EJ, Eriksen CW, Donchin E (1988) Pre- and poststimulus activation of response channels: A psychophysiological analysis. J Exp Psychol Hum Percept Perform 14, 331-344.

[91] Scheffers MK, Humphrey DG, Stanny RR, Kramer AF, Coles MG (1999) Error-related processing during a period of extended wakefulness. Psychophysiology 36, 149-157.

[92] Shackman AJ, Salomons TV, Slagter HA, Fox AS, Winter JJ, Davidson RJ (2011) The integration of negative affect, pain and cognitive control in the cingulate cortex. Nat Rev Neurosci 12, 154-167.

[93] Sharp DJ, Scott SK, Mehta MA, Wise RJS (2006) The neural correlates of declining performance with age: Evidence for age-related changes in cognitive control. Cereb Cortex 16, 1739-1749.

[94] Amieva H, Lafont S, Auriacombe S, Le Carret N, Dartigues J-F, Orgogozo J-M, Colette F (2002) Inhibitory breakdown and dementia of the Alzheimer type: A general phenomenon?. J Clin Exp Neuropsychol 24, 503-516.

[95] Grambaite R, Selnes P, Reinvang I, Aarsland D, Hessen E, Gjerstad L, Fladby T (2011) Executive dysfunction in mild cognitive impairment is associated with changes in frontal and cingulate white matter tracts. J Alzheimers Dis 27, 453-462.

[96] Burton CL, Strauss E, Bunce D, Hunter MA, Hultsch DF (2009) Functional abilities in older adults with mild cognitive impairment. Gerontology 55, 570-581.

[97] Perneczky R, Pohl C, Sorg C, Hartmann J, Komossa K, Alexopoulos P, Wagenpfeil S, Kurz A (2006) Complex activities of daily living in mild cognitive impairment: Conceptual and diagnostic issues. Age Ageing 35, 240-245.

[98] Endrass T, Klawohn J, Gruetzmann R, Ischebeck M, Kathmann N (2012) Response-related negativities following correct and incorrect responses: Evidence from a temporospatial principal component analysis. Psychophysiology 49, 733-743. 